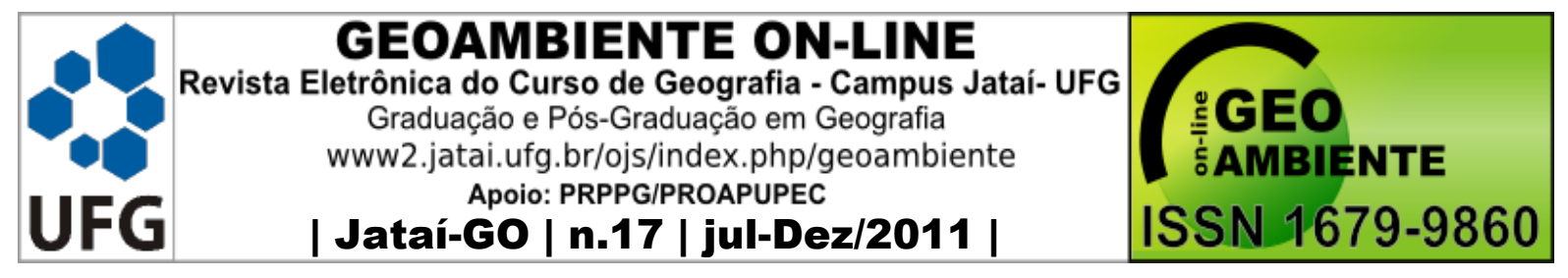

\title{
PERFIL SÓCIOECONÔMICO DOS PRODUTORES DE ABACAXI DO MUNICÍPIO DE LAGOA DE DENTRO, PARAÍBA
}

Leonel Antônio dos Santos Macêdo ${ }^{1}$, Anselmo Rodrigues de Oliveira ${ }^{2}$, Vinícius Batista Campos $^{3}$, José Félix de Brito Neto ${ }^{4}$, Damon Pereira dos Santos ${ }^{5}$

(1 - Universidade Federal da Paraíba, Eng. Agrônomo, leonelmadeco@yahoo.com.br; 2 Universidade Federal da Paraíba Eng. Agrônomo, Prof. CCA,UFPB, anselmorodrigues@yahoo.com.br; 3 - IFAP/Campus Laranjal do Jari, Agrônomo, Prof. MSc, doutorando em Engenharia Agrícola, CTRN, UFCG. Bolsista CNPq. vinicius.campos@ifap.edu.br; 4 - UNESP-Botucatu, Eng. Agrônomo, Doutorando em Produção Vegetal,. felix@fca.unesp.br; 5 - ULSAV-IDIARN, Eng. Agrônomo, MSc, damondos@yahoo.com.br)

\section{Resumo}

Com o objetivo de avaliar o perfil socioeconômico dos produtores de abacaxi do município de Lagoa de Dentro, Paraíba, realizou-se uma pesquisa, entre os meses de junho e outubro de 2007. Foram aplicados 30 questionários junto a produtores de forma direta, individual, ou coletiva, realizada nas propriedades, residências e associação de produtores de abacaxi. O estudo exploratório constitui-se de um questionário com 20 perguntas abertas e objetivas sobre o imóvel, as formas de produção, comercialização e condições socioeconômicas com que se desenvolve a produção. Os resultados comprovaram que mais de $70 \%$ são proprietários da terra, e o mesmo quantitativo participam de sindicato rural; a maioria dos produtores recebe assistência técnica pública. As principais práticas de manejo da cultura do abacaxi são realizadas de forma correta pelos produtores de Lagoa de Dentro.

Palavras-chave: Ananas comosus; agreste; sistema de produção

\author{
Abstract \\ SOCIOECONOMIC PROFILE OF PINEAPPLE PRODUCERS OF THE CITY OF \\ LAGOA DE DENTRO, PARAÍBA STATE, BRAZIL
}

\footnotetext{
Artigo recebido para publicação em 16 de Agosto de 2011

Artigo aprovado para publicação em 15 de Dezembro de 2011
} 


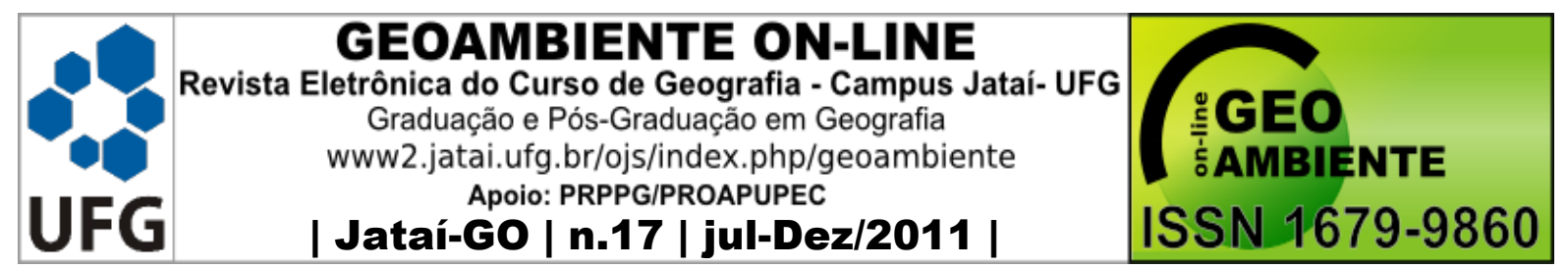

In order to assess the socioeconomic profile of pineapple producers in the municipality of Lagoa de Dentro, Paraíba, a survey was held between the months of June and October 2007. We applied 30 questionnaires to producers directly, individual or collective, held in the properties, homes and pineapple growers' association. The exploratory study consisted of a questionnaire with 20 questions open and objective about the property, the means of production, marketing and socioeconomic conditions in which the production unfolds. The results showed that over $70 \%$ are owners of the land, and the same number of unions participating rural, with most producers receive public assistance. The main management practices of the culture of pineapple are properly carried out by producers in the city of Lagoa de Dentro.

Keywords: Ananas comosus; agreste; production system

\section{Resumen}

\section{PERFIL SOCIOECONÓMICO DE LOS PRODUCTORES DE PIÑA DE LA CIUDAD DE LAGOA DE DENTRO, EL ESTADO DE PARAÍBA, BRASIL}

A fin de evaluar el perfil socioeconómico de los productores de piña en el municipio de Lagoa de Dentro, Paraíba, una encuesta se llevó a cabo entre los meses de junio y octubre de 2007. Se aplicaron 30 cuestionarios a los productores directamente, individual o colectiva, que se celebró en las propiedades, casas y asociación de productores de piña ". El estudio exploratorio consistió en un cuestionario con 20 preguntas abiertas y objetiva sobre la propiedad, los medios de producción, comercialización y las condiciones socioeconómicas en que se desarrolla la producción. Los resultados mostraron que más del $70 \%$ son propietarios de la tierra, y el mismo número de sindicatos participantes rural, con la mayoría de los productores reciben asistencia pública. Las prácticas de gestión principal de la cultura de la piña se realicen adecuadamente por los productores de la Lagoa de Dentro.

Palabras-chave: Ananas comosus; agreste; sistema de produción

\section{1 - Introdução}

O abacaxizeiro é pertencente à família das Bromeliáceas, classificado botanicamente como uma infrutescência, da classe das monocotiledôneas, tem como centro de origem a América latina, mais precisamente Brasil e Paraguai. De acordo com a FAO (2005), o Brasil é quarto maior produtor mundial de abacaxi, contribuindo com 9,4\% em relação ao total 


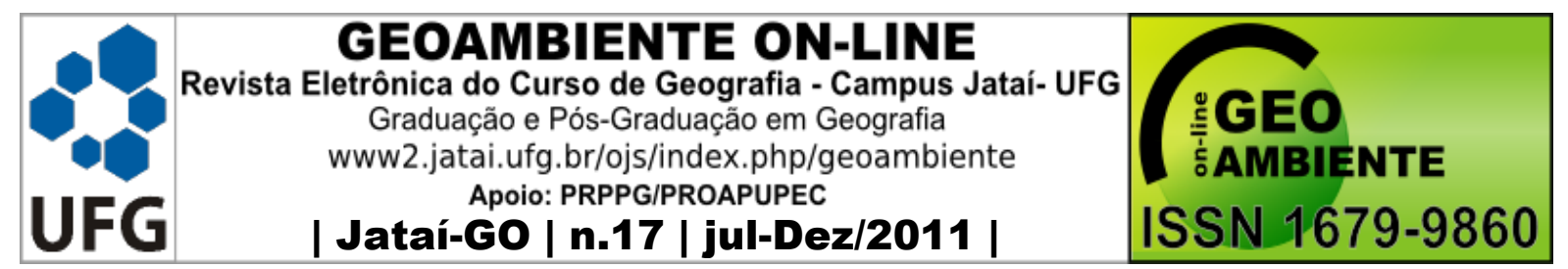

produzido, tendo a exploração desta cultura em quase todos os Estados (BRITO NETO, 2006).

O abacaxi é caracterizado como um fruto muito apreciado em todo o mundo, tanto na forma natural, quanto industrializada; mais de $90 \%$ do abacaxi produzido no Brasil é consumido in natura, com perdas girando em tomo de $10-15 \%$ do total colhido. Sua importância socioeconômica para o país deve-se a suas excelentes características organolépticas (sabor, coloração, aparência), que reflete numa maior aceitabilidade pelos consumidores. No Brasil, as cultivares mais plantadas é a "Pérola" e a "Smooth cayene", sendo a Pérola considerada a mais consumida in natura, graças às qualidades físicas e químicas de sua polpa (GONÇALVES e CARVALHO, 2000).

Esta frutífera é difundida em praticamente todo o território nacional, destacando-se como os principais produtores, Pará, Minas Gerais, Paraíba e Tocantins; Sendo a Paraíba o principal Estado produtor do país (IBGE, 2006).

Preconizada como a cultura de maior expressão econômica dentro do setor frutícola para o estado da Paraíba, o abacaxi gera centenas de empregos diretos e indiretos durante todo o ciclo da cultura, tal fato se deve a baixa mecanização utilizada em seu cultivo, necessitandose da mão de obra humana. Na Paraíba, o abacaxi é explorado em mais de 27 municípios, os quais se localizam em sua maioria na Zona da Mata, destacando-se os municípios de Santa Rita, Itapororoca, Araçagi e Sapé. Devido ao significativo retorno econômico que o abacaxi apresenta vários outros municípios vêm se destacando com a exploração desta cultura, como por exemplo, o município de Lagoa de Dentro. Esta cultura abrange várias camadas no setor agrícola, pois envolve desde o pequeno agricultor que tem a mão de obra da família como principal ferramenta para o desenvolvimento do seu plantio, como também grandes produtores, que contratam pessoas (diaristas) para trabalhar em seus plantios (MOLINA, 2007).

Nesse sentido, objetivaram-se obter, por meio de um estudo exploratório, informações referentes ao processo produtivo do abacaxi no município de Lagoa de Dentro, visando gerar informações que possam ser utilizadas como política para o fortalecimento e desenvolvimento da abacaxicultura no município de Lagoa de Dentro e na Paraíba.

\section{2 - Material e Métodos}

Esta pesquisa foi desenvolvida no período compreendido entre os meses de Junho e Outubro de 2007, através da aplicação de 30 questionários junto a produtores de forma direta, 


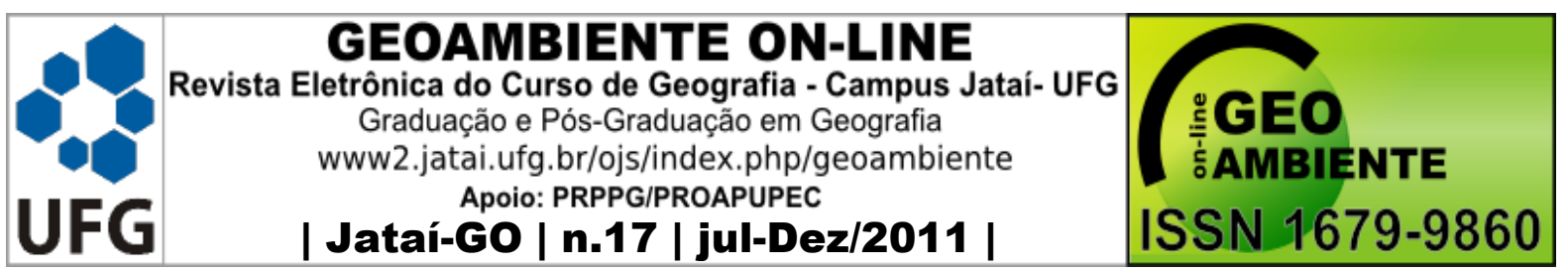

individual, ou coletiva, realizada nas propriedades, residências e associação de produtores de abacaxi. Os 30 questionários estruturados foram distribuídos em comunidades produtoras do fruto, de forma aleatória abrangendo do pequeno ao grande produtor.

O campo de pesquisa foram comunidades rurais que produzam abacaxi no município de Lagoa de Dentro (Figura 1), os quais serão amostrados através da aplicação de questionários estruturados. O município foi definido em função da sua crescente participação na produção estadual.

Figura 1. Localização geográfica do município de Lagoa de Dentro, Paraíba.

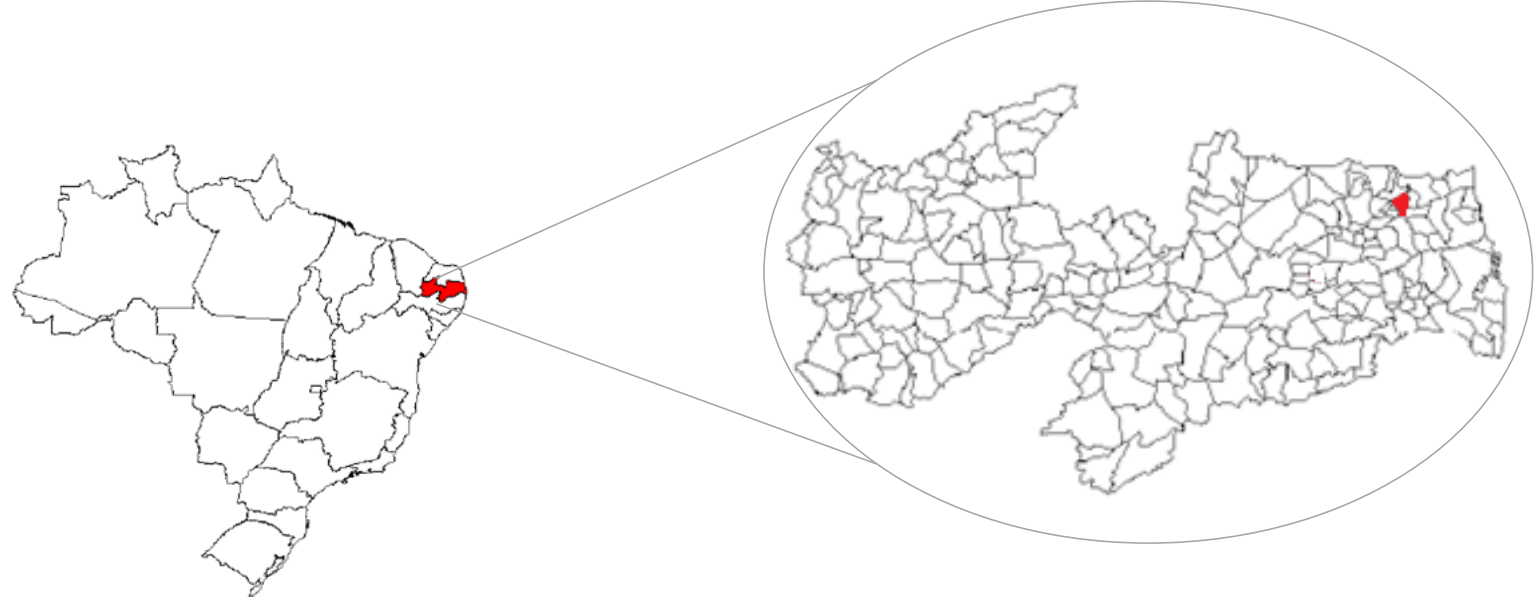

Elaborado por Vinícius Batista Campos

Os produtores foram escolhidos de forma aleatória dentro de um universo de produtores de abacaxi que compreenda do pequeno ao grande produtor. Estes produtores foram entrevistados em áreas de assentamento de reforma agrária, comunidades de agricultores tradicionais e áreas de agricultura patronal, possibilitando assim a verificação das formas de produção.

O estudo exploratório constitui-se de um questionário com 14 perguntas abertas e objetivas sobre o imóvel, as formas de produção, comercialização e condições sócio econômicas com que se desenvolve a produção.

Após a coleta e tabulação dos dados, foi realizado uma análise desses, com auxílio de planilha computacional, para posterior confecção dos gráficos.

\section{3 - Resultados e Discussão}




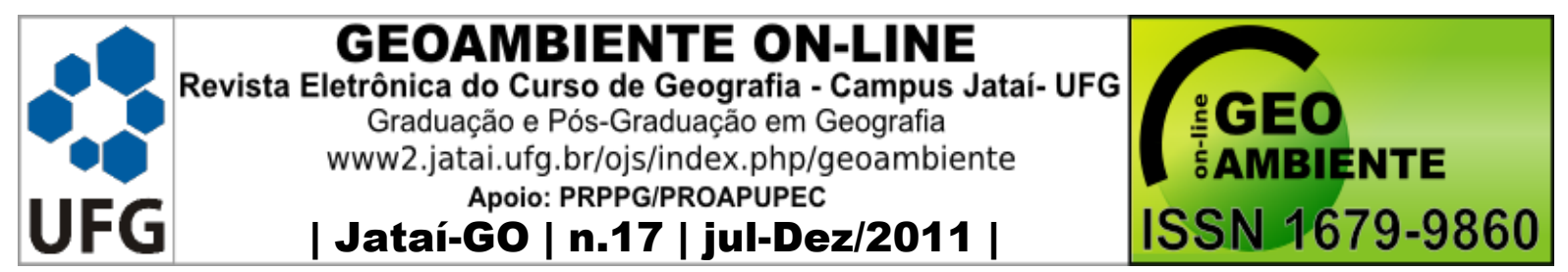

O Brasil é um país de dimensões continentais, detentor de grandes áreas de terras, e boa parte delas agricultáveis. Dentre o processo produtivo agrícola ou agropecuário, a terra apresenta-se como base fundamental para a efetivação desse processo.

A falta desse recurso dificulta e onera o processo de produção agrícola, visto que em muitas das vezes, a saída é o arrendamento de terras. Tal fato é verificado com muita frequência na abacaxicultura paraibana. Brito Neto (2006), verificou em estudos realizados que cerca de $28 \%$ dos produtores de abacaxi na Paraíba, produzem o abacaxi em áreas arrendadas.

Estes dados corroboram com os encontrados em pesquisa realizada no município de Lagoa de Dentro, onde se verificou que $27 \%$ dos produtores desse município produzem abacaxi em áreas arrendadas (Figura 2). Entretanto, Barreiro Neto et al. (2002), em estudo realizado verificou que $50 \%$ do universo dos produtores pertencem a categoria de proprietários, seguido pelo arrendatário com $39,17 \%$.

Figura 2. Regime de posse da terra dos produtores de abacaxi em Lagoa de Dentro - PB.

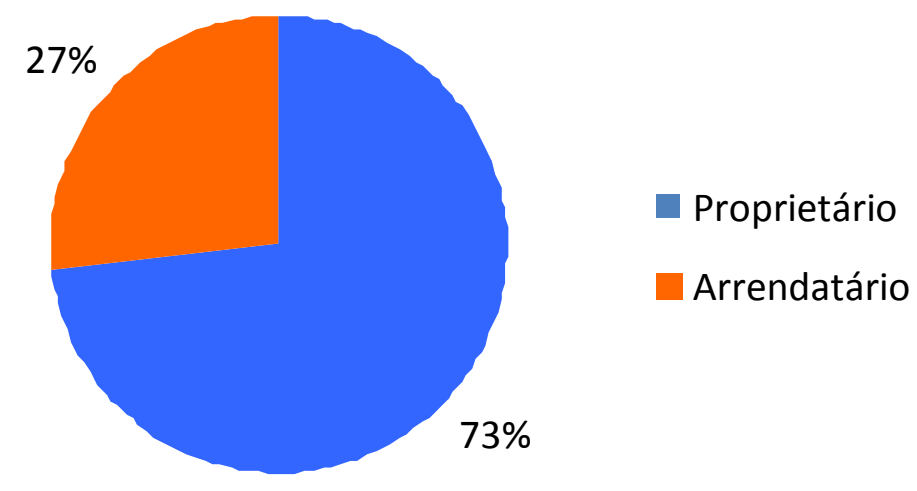

Fonte: Pesquisa de campo

No meio rural, as associações, cooperativas e sindicatos, tem se mostrado de fundamental importância para a organização do setor e promover o desenvolvimento de comunidades e municípios. Observando-se a Figura 3, pode-se verificar que apenas $27 \%$ dos produtores de abacaxi do município de Lagoa de Dentro participam do sindicato rural, ou seja, mais de $70 \%$ dos produtores não participam de nenhuma forma de organização. Brito Neto (2006), estudando as formas de organização dos produtores de abacaxi no Estado da 


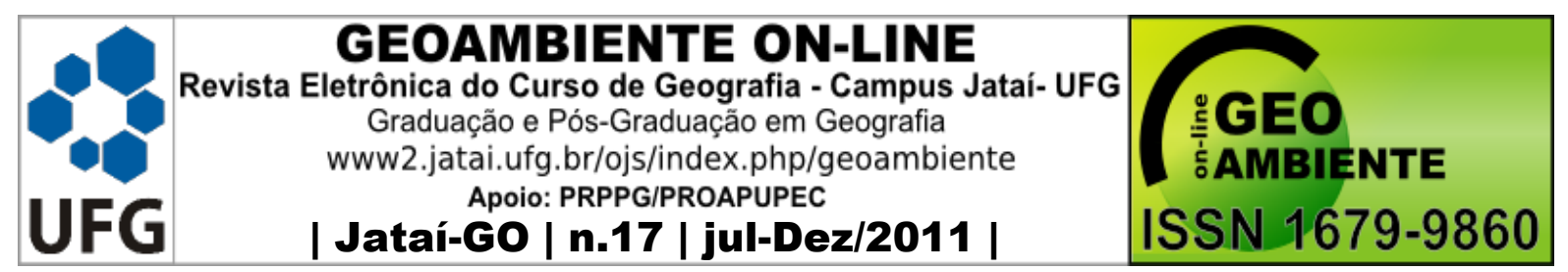

Paraíba, verificou que apenas cerca de $13 \%$ dos produtores participavam de cooperativas, com destaque para o município de Santa Rita, o qual apresenta o maior nível de organização dentre os municípios pesquisados.

Barreiro Neto et al. (2002), em estudo realizado verificou que a comercialização via bolsa de comercialização representa $4,17 \%$ do total comercializado, e que ainda prevalece à forma tradicional de comercialização via terceiros atingindo $75,83 \%$.

Figura 3. Formas de organização dos produtores de abacaxi de Lagoa de Dentro - PB.

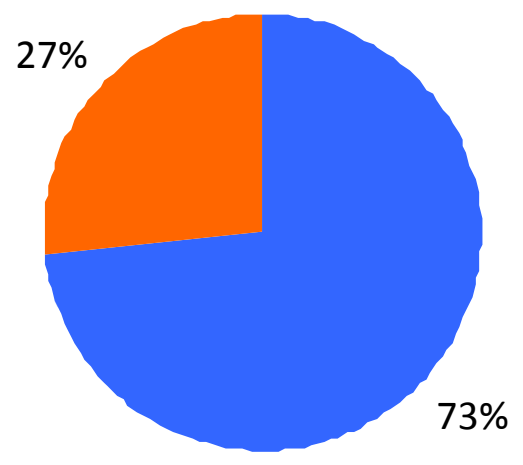

Sindicato de trabalhadores rurais

Nenhuma

Fonte: Pesquisa de campo

As políticas de financiamento agrícola no Brasil têm em muitos casos se apresentado com arma de exclusão de pequenos produtores, fato atribuído a enorme exigência e burocracia feita pelos agentes financeiros aos produtores que procuram estas instituições no intuito de fazer um financiamento bancário. Brito Neto (2006), verificou que cerca de $63 \%$ dos produtores de abacaxi no Estado da Paraíba, utilizam financiamento bancário, no entanto, ainda se verifica que uma parcela desses produtores utilizam financiamentos de terceiros. Entretanto, Barreiro Neto et al. (2002) verificou em estudo realizado que $43 \%$ dos produtores entrevistados não têm acesso ao crédito rural.

Observando-se a Figura 4, pode-se observar que no município de Lagoa de Dentro, $70 \%$ dos produtores realizam financiamentos bancários para o cultivo do abacaxi, no entanto, ainda percebe-se que uma pequena parcela dos produtores daquele município, $10 \%$ ainda utilizam financiamentos de terceiros, na maioria das vezes atravessadores, que financiam parte do processo produtivo com o objetivo de assegurar a compra da produção, o que torna o produtor dependente desses atravessadores, pois dessa forma, o produtor está sujeito a vender 


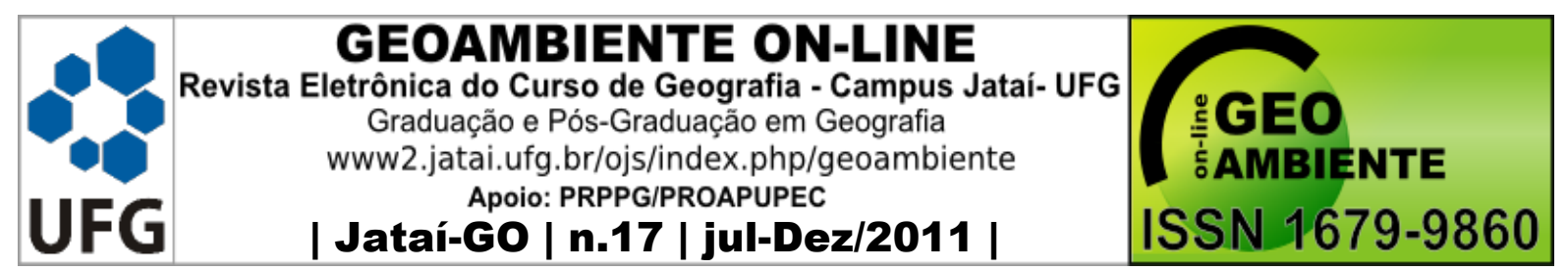

a produção pelo preço ditado por eles, ou seja, muito abaixo do preço de mercado. Estes dados corroboram com os valores encontrados por Brito Neto (2006).

Figura 4. Formas de financiamento da produção de abacaxi em Lagoa de Dentro - PB.

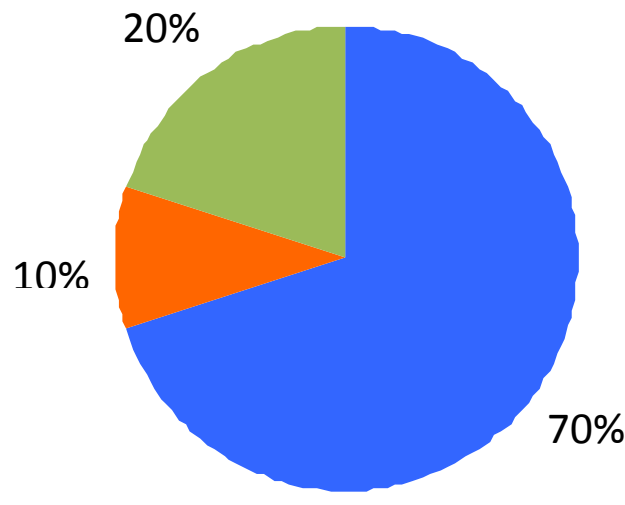

Bancos

financeiros

Financiadores-

compradores

Nenhum

Fonte: Pesquisa de campo

A assistência técnica e a extensão rural pública até a década de 90 eram restritas as iniciativas isoladas de alguns profissionais, por que a maioria tinha sua formação profissional nos moldes de revolução verde, desvalorizando os conhecimentos dos produtores (FONSECA, 2002).

Na Figura 5, pode-se verificar que $65 \%$ dos produtores de abacaxi do município de Lagoa de Dentro recebem assistência técnica através da EMATER, o que favorece o processo produtivo através de orientação técnica. Estes dados corroboram com os encontrados por (BRITO NETO, 2006), verificou em estudo realizado que $40 \%$ dos produtores desse município recebem assistência.

A água é um recurso imprescindível dentro do processo de produção agrícola, tornando-se um fator condicionante em muitas das vezes. Sua utilização na prática de irrigação permite que o produtor possa planejar a época de colheita da produção, produzindose assim na entressafra, permitindo-lhe obter melhores preços. 


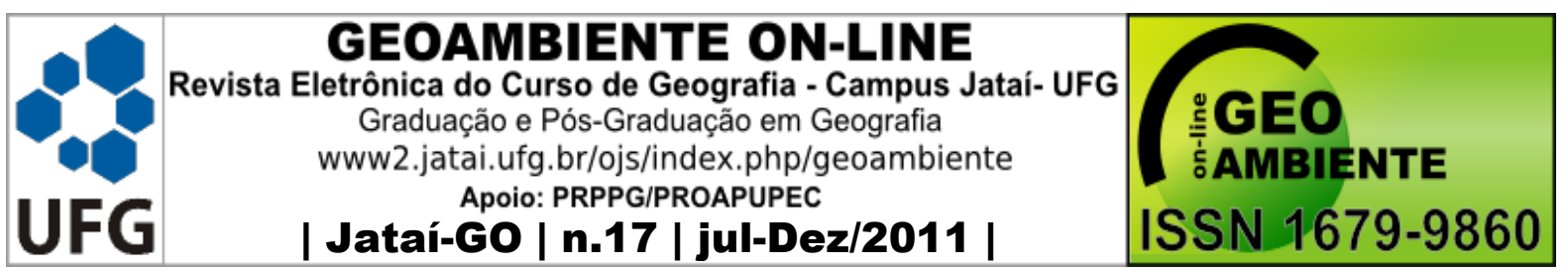

Figura 5. Assistência técnica rural às áreas produtoras de abacaxi em Lagoa de Dentro - PB

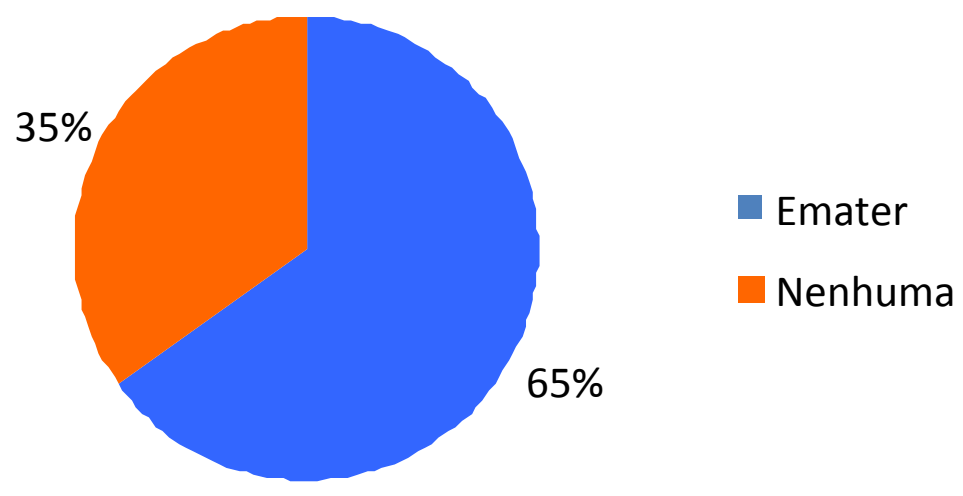

Fonte: Pesquisa de campo

A safra do abacaxi no Estado da Paraíba começa de forma gradativa no mês de agosto, tendo seu pico no mês de outubro, estendendo-se até o mês de janeiro, isto cultivado na forma de sequeiro. De acordo com a Figura 6, pode-se verificar que no município de Lagoa de Dentro a maior parte do abacaxi é produzido no período da safra, ou seja, plantio de sequeiro, pois $81 \%$ dos produtores não praticam irrigação, o que faz com que se obtenham menores preços.

Figura 6. Utilização de irrigação pelos produtores de abacaxi de Lagoa de Dentro - PB.

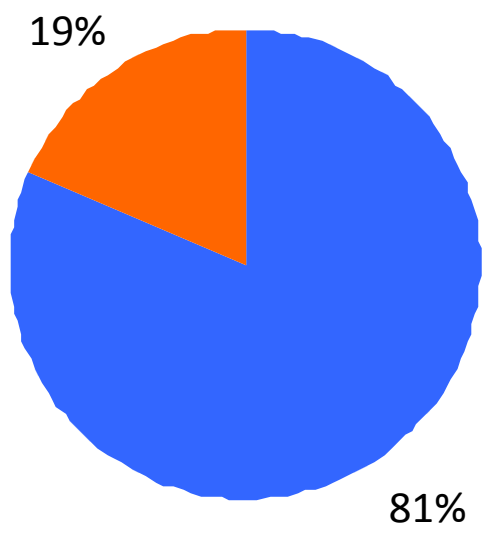

Nenhuma

Irrigação por

arpersão

Fonte: Pesquisa de campo 


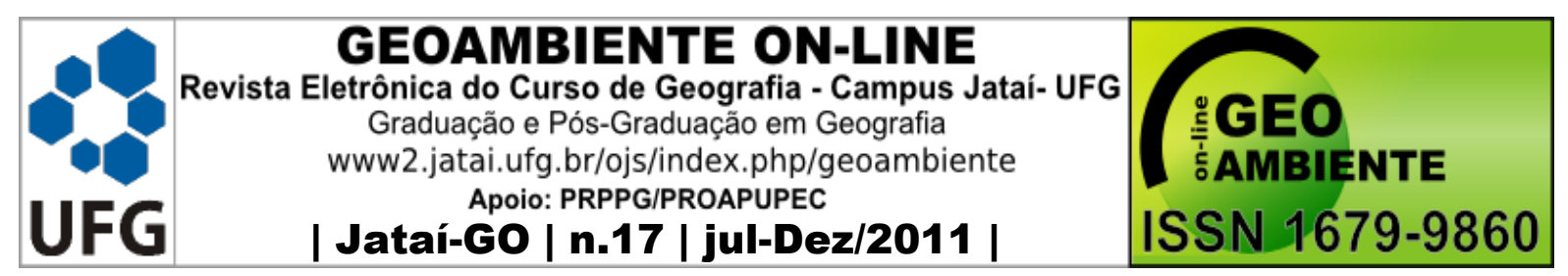

Dados semelhantes foram observados por Brito Neto (2006), pois o mesmo verificou que apenas $20 \%$ dos produtores do município de Lagoa de Dentro praticam irrigação. Estes dados corroboram com os valores encontrados por Barreiro Neto et al. (2002), que verificou que $74,17 \%$ da produção de abacaxi na Paraíba é realizada em regime de sequeiro.

Tal fato, muitas das vezes encarece o processo produtivo e compromete a qualidade físico-química do abacaxizeiro.

Brito Neto (2006) em estudo realizado na Paraíba, verificou que a maior parte dos produtores de abacaxi prima pela boa nutrição das plantas de abacaxi, realizando três adubações por ciclo cultural. No entanto, analisando a Figura 7, verifica-se que no município de Lagoa de Dentro, apenas $35 \%$ dos produtores realizam três adubações, sendo que a maior parte deles $60 \%$ realiza apenas duas adubações. Barreiro Neto et al. (2002), verificou que $30 \%$ dos produtores realizam duas adubações durante o ciclo da cultura.

Figura 7. Quantidade de adubação aplicada pelos produtores de Lagoa de Dentro - PB.

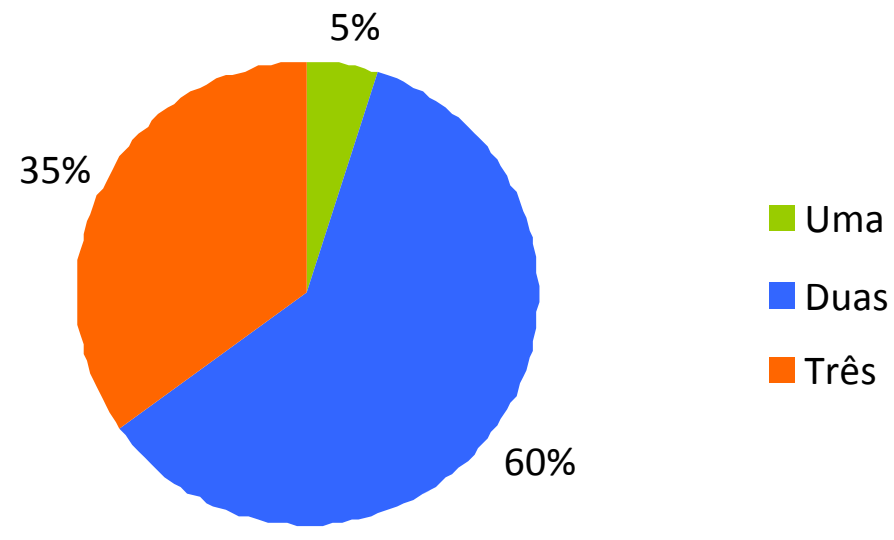

Fonte: Pesquisa de campo

A qualidade e a quantidade adequada de fertilizante fornecida à planta são de suma importância para se obter uma boa produção e ótima qualidade de frutos. Com a formatação das tabelas de adubação, foi possível difundir no meio rural as diversas formulações de adubos referentes a cada cultura, no entanto, muitas das vezes fornece-se um determinado nutriente em excesso e outro de forma deficiente, promovendo assim, um desequilíbrio nutricional na planta. 


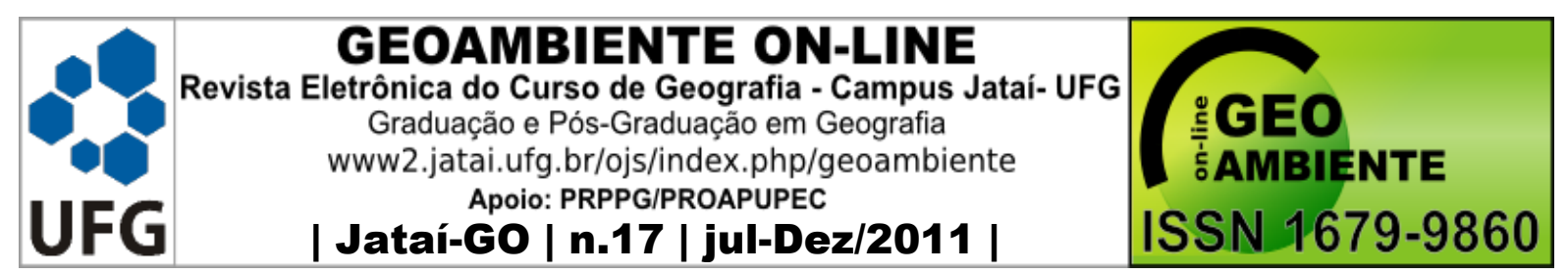

Dessa forma, o mais indicado é formular o fertilizante de acordo com o estado nutricional do solo e as exigências da cultura. De acordo com a Figura 8, pode-se verificar que no município de Lagoa de Dentro, apenas $5 \%$ dos produtores de abacaxi formulam seu próprio adubo, ou seja, $95 \%$ dos produtores utilizam fórmulas comerciais.

Figura 8. Tipo de adubos utilizados pelos produtores de abacaxi de Lagoa de Dentro - PB.

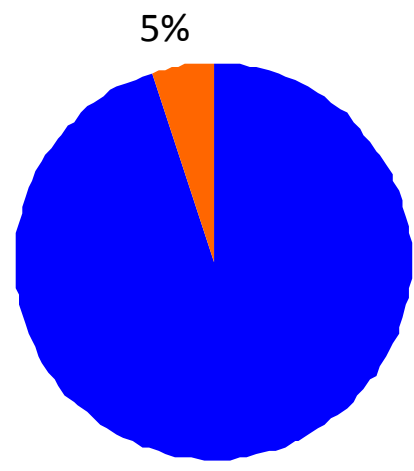

$95 \%$
Fórmulas

comerciais

Formula seu próprio adubo

Fonte: Pesquisa de campo

De acordo com os dados da Figura 9, as propriedades em estudo, mais da metade, ou seja, 55\% são consideradas como médias propriedades, sendo considerada como média propriedade aquelas variando entre três e 10 ha. Já $45 \%$ do total avaliado através de questionário, foram $45 \%$, considerados como pequenos produtores de abacaxi, ou seja, possuindo áreas inferiores a três ha plantados. Esses resultados encontram-se semelhantes aos observados por Brito Neto (2006), onde cerca de $67 \%$ dos produtores de abacaxi do Estado da Paraíba possuem uma área plantada variando entre 1 e 5 ha.

A forma de trabalho empenhada nas propriedades (Figura 10), ou seja, como se encontram a forma de emprego dentro das propriedades. Constata-se que, cerca de $65 \%$ dos entrevistados encontram-se como diarista, já cerca de 35\%, observam-se como trabalho através de empreitada. Tendências similares foram observadas por IGBE (2006), onde, a maior parte dos produtores contrata pessoas (diaristas) para trabalhar em seus plantios. 


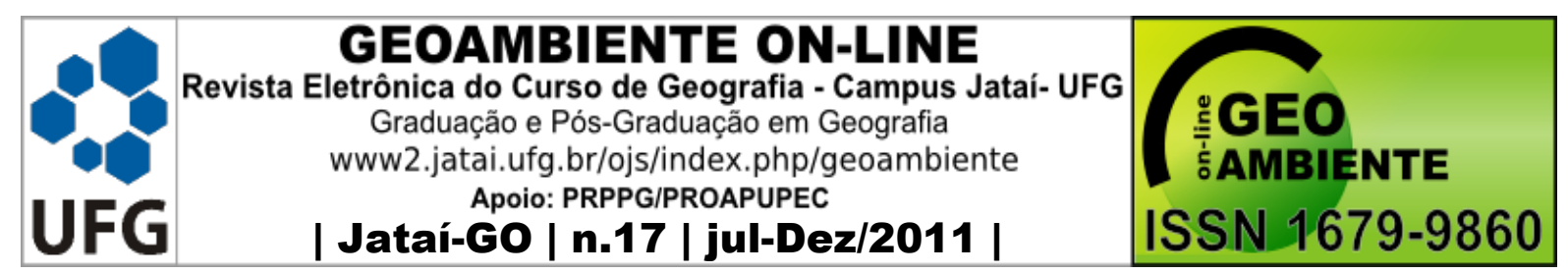

Figura 9. Dimensão (ha) das propriedades produtoras de abacaxi de Lagoa de Dentro - PB

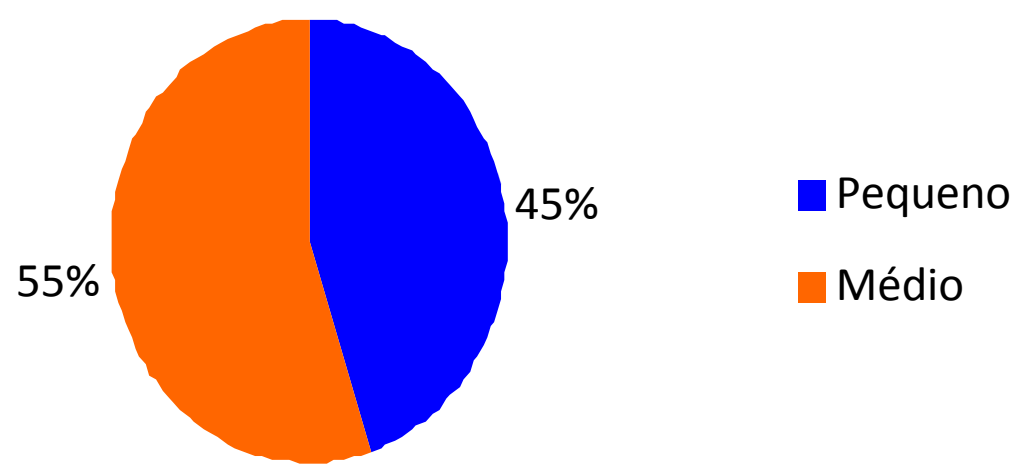

Fonte: Pesquisa de campo

Figura 10. Forma de trabalho requisitada pelos produtores de Lagoa de Dentro - PB

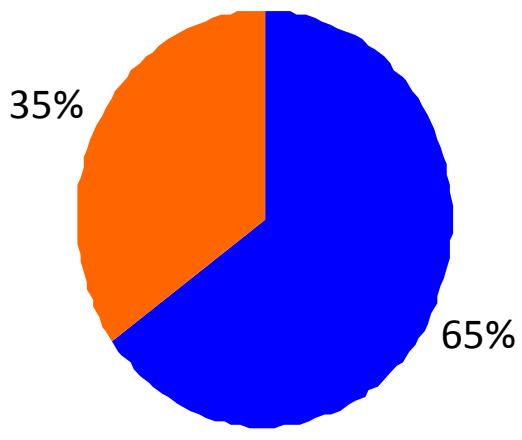

Diarista

Empreita

Fonte: Pesquisa de campo

A rotação de cultura (Figura 11) é utilizada pela maioria dos produtores de Lagoa de Dentro, cerca de $70 \%$. Entretanto, os demais produtores (30\%), inutilizam essa prática. Segundo Brito Neto (2006), o emprego da rotação de cultura possui várias vantagens tais como: Proporciona a produção diversificada de alimentos e outros produtos agrícolas, se adotada e conduzida de modo adequado e por um período suficientemente longo, essa prática melhora as características físicas, químicas e biológicas do solo; auxiliam no controle de plantas daninhas, doenças e pragas; repõe matéria orgânica e protege o solo da ação dos agentes climáticos e ajuda a viabilização do sistema de semeadura direta e dos seus efeitos benéficos sobre a produção agropecuária e sobre o ambiente como um todo. 


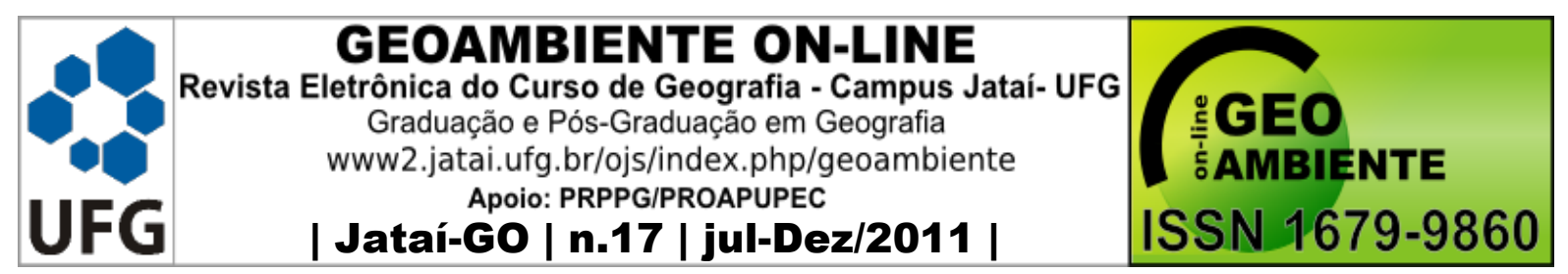

Figura 11. Uso de rotação de cultura pelos produtores de abacaxi de Lagoa de Dentro - PB

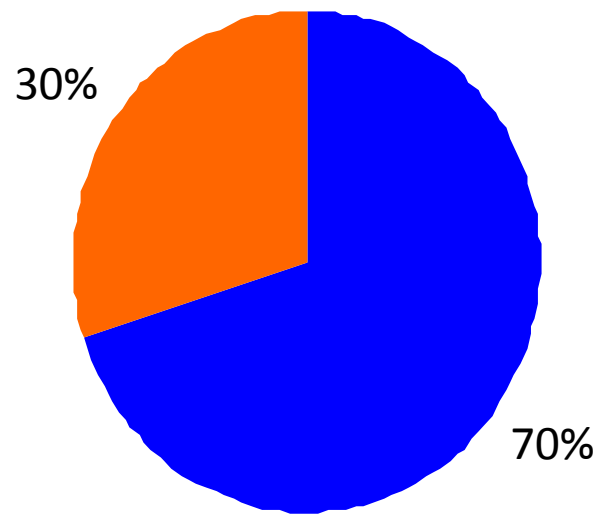

Sim

Não

Fonte: Pesquisa de campo

A utilização dessas plantas deve ser baseada no conhecimento da relação entre elas e os diferentes nematóides que ocorrem na área. Por exemplo, a cana-de-açúcar, frequentemente cultivada em áreas de produção de abacaxi, é uma má hospedeira de R.reniformis, porém uma boa hospedeira de P. brachyurus e M. incógnita.

Os tratamentos das mudas é uma prática de fundamental importância para o início da atividade abacaxicultura (Figura 12), mesmo assim, metade dos produtores entrevistados no município de Lagoa de Dentro (50\%), não realiza algumas atividades que favorecem um melhor estabelecimento das mudas. De acordo com Cunha (1999), as mudas, antes de serem colhidas, devem passar por um processo de "ceva" - período de crescimento no cacho ainda aderido à planta-mãe, e também, ser isentas de pragas, outras doenças e danos mecânicos. Quando colhidas em período chuvoso, as mudas precisam passar por um período de "cura" exposição ao sol, com a base voltada para cima, durante cerca de uma semana. A cura permite apressar a cicatrização da parte lesionada quando da separação do cacho, eliminar o excesso de umidade e facilitar a seleção. A cura não é necessária, quando as mudas passaram por período prolongado de deficiência hídrica, evitando-se a sua desidratação excessiva.

No que se refere ao uso de adubação orgânica (Figura 13), a maioria produtores do município de Lagoa de Dentro (75\%), não usam de adubação orgânica, sendo como fonte o esterco bovino. Contudo, cerca de $25 \%$ dos produtores desempenham a prática de adubação com fontes orgânicas. Segundo Cunha (1999), a utilização de adubos orgânicos (estercos, tortas vegetais, compostos), quando possível, é particularmente importante nos solos de 


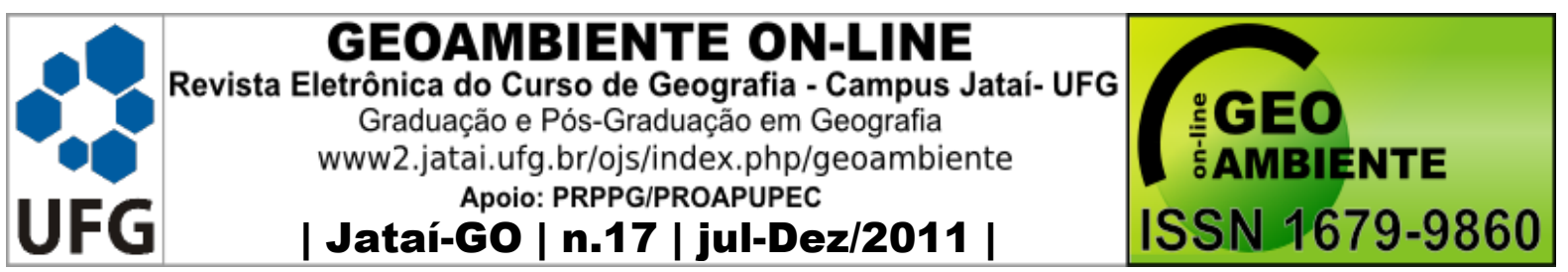

textura arenosa e pobres em matéria orgânica, muito frequentes na Região de Itaberaba, local de expressão econômica da cultura. Estes adubos devem, em princípio, ser aplicados por ocasião do plantio ou na primeira adubação em cobertura.

Figura 12. Tratamento das mudas utilizadas pelos produtores de abacaxi de Lagoa de Dentro $-\mathrm{PB}$

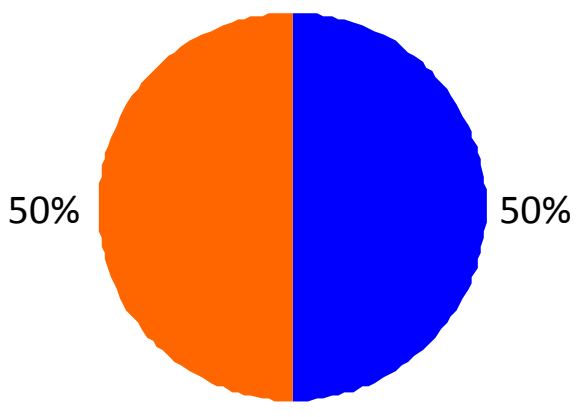

Sim

Não

Fonte: Pesquisa de campo

Figura 13. Uso de adubação orgânica pelos produtores de abacaxi de Lagoa de Dentro - PB

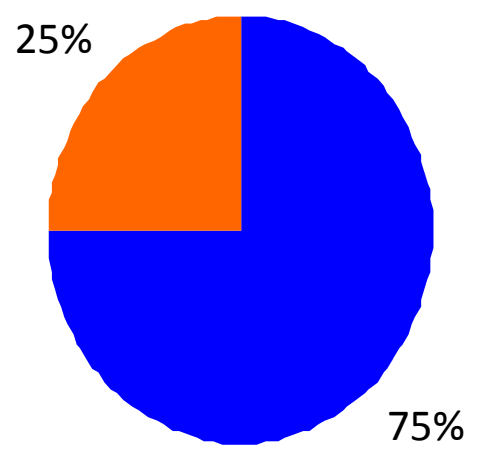

Nenhuma

Estercobovino

Fonte: Pesquisa de campo

A incorporação dos restos culturais do abacaxi (Figura 14) é realizada pela maioria dos produtores de abacaxi, ou seja, cerca de $82 \%$, porém, mesmo tendo consciência dos benefícios que a mesma realiza à cultura, cerca de $18 \%$ preferem não realizar essa prática. 


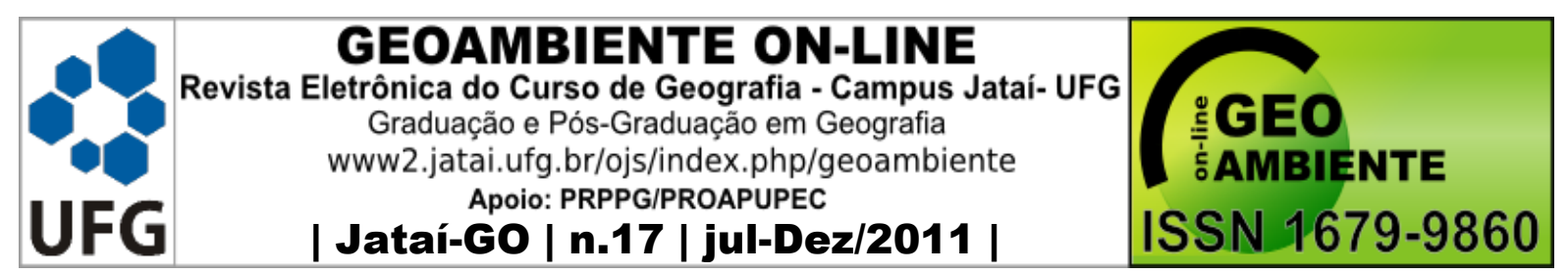

Para Souza (2006), os restos culturais da cultura do abacaxi (Ananas comosus L.

Merrill) compreendem as plantas que ficam no campo, após a colheita dos frutos e das mudas. Normalmente estes restos culturais são vistos como "problema", sobretudo pelos pequenos produtores, que, na premência de logo "desocupar a terra" para novos plantios, recorrem aos meios mais rápidos e menos trabalhosos para se "livrar" deles. Nestas circunstâncias, a queima do material tem sido uma alternativa usada com muita frequência para sanar a dificuldade. O mesmo autor ainda ressalta que restos culturais representam valores entre $60 \mathrm{e}$ 150 toneladas de massa verde por hectare.

Admitindo-se que essas plantas têm em torno de $20 \%$ de matéria seca, podem-se estimar quantidades de matéria orgânica que variam de 12 a 30 toneladas por hectare. Nessa matéria orgânica estão normalmente contidas quantidades expressivas de nutrientes, que, em números redondos, podem chegar a ultrapassar $200 \mathrm{~kg}$ de $\mathrm{N}, 100 \mathrm{~kg}$ de $\mathrm{P}_{2} \mathrm{O}_{5}, 800 \mathrm{~kg}$ de $\mathrm{K}_{2} \mathrm{O}$, $30 \mathrm{~kg}$ de $\mathrm{Ca}$ e $60 \mathrm{~kg}$ de $\mathrm{Mg}$ por hectare.

Figura 14. Incorporação dos restos vegetais pelos produtores de abacaxi de Lagoa de Dentro -

PB

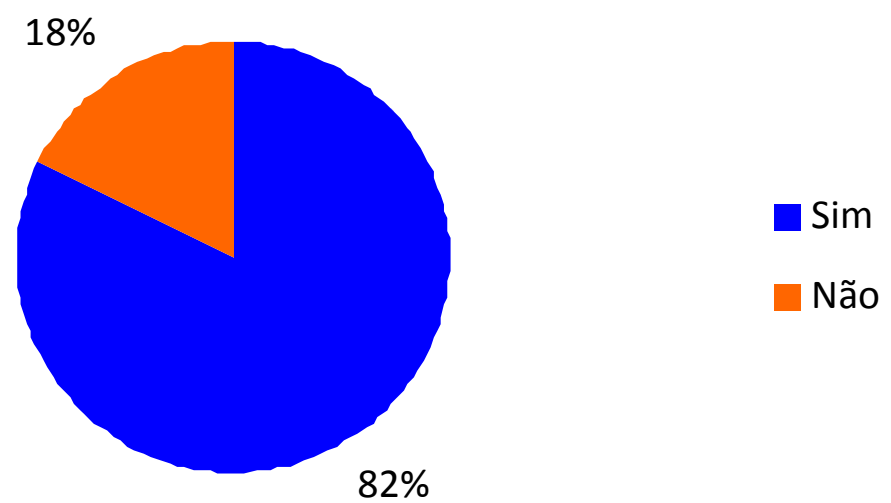

Fonte: Pesquisa de campo

\section{4 - Conclusões}

- A assistência técnica aos produtores de abacaxi de Lagoa de Dentro, na maioria dos casos, é atuante, diferente de outras localidades e atividades agropecuárias no âmbito estadual; 


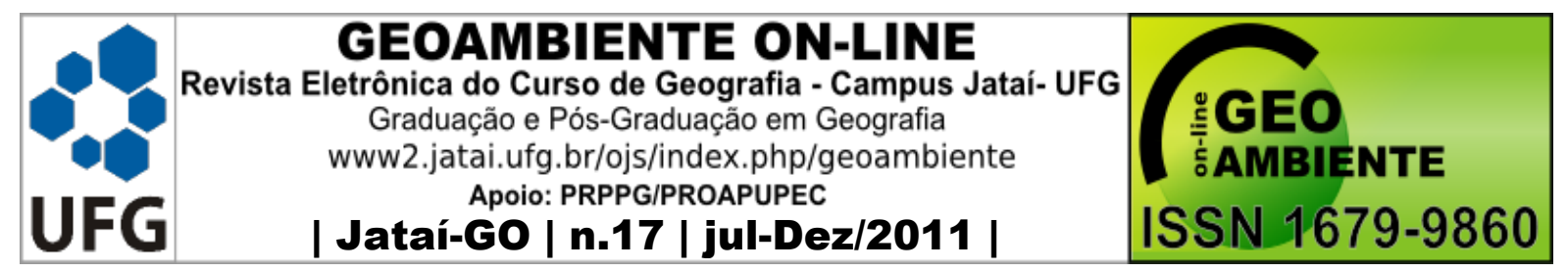

- A área destinada para plantio de abacaxi em Lagoa de Dentro encontra-se dentro das realidades estadual e nacional;

- Exceto na irrigação e adubação orgânica, as principais atividades de manejo da cultura do abacaxi são realizadas pela maioria dos produtores do município estudado.

\section{5 - Bibliografia}

BARREIRO NETO, Miguel; SANTOS, Élson Soares dos; SANTOS, João Felinto dos. Aspectos socioeconômicos da abacaxicultura no estado da Paraíba. In: BARREIRO NETO, M.; SANTOS, E.S. dos (Eds.). Abacaxi: da agricultura familiar ao agronegócio. João Pessoa: EMEPA-PB, 2002. cap. 7, p. 85-98.

BRITO NETO, José Félix de. Diagnóstico Produtivo e Socioeconômico da Abacaxicultura Paraibana. 52 f. 2006. Trabalho de Conclusão de Curso. (Graduação em Engenharia Agronômica) - Universidade Federal da Paraíba.

CUNHA, G.A.P. da. Implantação da cultura. In: CUNHA, G.A.P. da; CABRAL, J.R.S.; SOUZA, L.F. da. (organizadores). O abacaxizeiro cultivo, agroindústria e economia. Brasília: Embrapa Comunicação para Transferência de Tecnologia, 1999. p.139-167.

FAO. Base de dados produção de frutas. Disponível em: <http://www.fao.org/inicio.htm>. Acesso em: 20 de maio de 2005.

FONSECA, Maria Fernanda Albuquerque; WILKINSON, John. As oportunidades e os desafios da agricultura orgânica. In: LIMA, D.M.; WILKINSON, J. (ORG). Inovação nas tradições da agricultura familiar. Brasília: CNPq/Paralelo 15, 2002.p.249-280. GONÇALVES, N. B; CARVALHO, V. D. de. Características da fruta. In: GONÇALVES, N. B. Abacaxi: pós-colheita. Brasília, DF: Embrapa/CTT, 2000. p. 13-27. (Frutas do Brasil, $5)$.

IBGE - Sistema IBGE de Recuperação Automática - SIDRA. Levantamento sistemático da produção. Disponível em: <http://www.sidra.ibge.gov.br>. Acesso em 10 de maio de 2006.

MOLINA, Leôncio Vilar. O abacaxi paraibano. Disponível em: http://www.todafruta.com.br. Acesso em 22 de março de 2007.

SOUZA, Luiz Francisco da Silva. Os restos culturais do abacaxizeiro e o solo. Disponível em: www.nordesterural.com.br/nordesterural/matler.asp?newsId=3236. Publicado em 04 de janeiro de 2006. 